\title{
Neutraal of sekularisties, humanisties en paganisties: Die alternatiewe godsdiens van die Weste?
}

\author{
Author: \\ Pieter Verster ${ }^{1}$ \\ Affiliation: \\ ${ }^{1}$ Faculty of Theology, \\ University of the Free State, \\ South Africa \\ Correspondence to: \\ Pieter Verster \\ Email: \\ versterp@ufs.ac.za \\ Postal address: \\ PO Box 29115, Danhof 9310, \\ South Africa

\section{Dates:} \\ Received: 26 July 2012 \\ Accepted: 09 Oct. 2013 \\ Published: 14 Nov. 2013 \\ How to cite this article: \\ Verster, P., 2013, 'Neutraal of \\ sekularisties, humanisties en \\ paganisties: Die alternatiewe \\ godsdiens van die Weste?', \\ In die Skriflig/In Luce Verbi \\ 47(1), Art. \#174, 10 pages. \\ http://dx.doi.org/10.4102/ \\ ids.v47i1.174
}

\section{Copyright:}

(C) 2013. The Authors. Licensee: AOSIS OpenJournals. This work is licensed under the Creative Commons Attribution License.

Read online:
Die soeke na neutraliteit in die wetenskapsbeoefening van die Weste het daartoe gelei dat 'n alternatiewe godsdiens na vore gekom het. Hierdie godsdiens is sekularisties, humanisties en paganisties. Die Christelike grondslae is verruil vir uitgangspunte wat die Christelike boodskap ondergrawe. Is daar 'n Christelike antwoord op die problematiek van die alternatiewe godsdiens wat in die Weste na vore kom? Die Christelike boodskap behoort 'n volledige en omvattende saak te wees. Wetenskap wat vanuit 'n Christelike geloofsperspektief beoefen word, behoort daarom onder andere die volgende aspekte te vertoon: 'n Verruimende perspektief van die erkenning van God, waarin die vryheid in Christus die ware vryheid tot die lewe is; ook medemenslikheid in die wetenskapsbeoefening vanuit die perspektief dat God die Een is wat in Jesus Christus die ware lewe gee. 'n Eskatologiese perspektief moet ook nie ontbreek nie. Die reformatoriese vernuwing van die samelewing en veral die wetenskap vereis die erkenning van Jesus Christus se lewensomvattende invloed en heerskappy. Hierdie apekte sal in die artikel bespreek word.

Neutral or secularistic, humanistic and paganistic: The alternative religion of the West? In search for neutrality in the scientific endeavour in the West an alternative religion was established. This religion is secularistic, humanistic and paganistic. Christian views in science and society were changed for views that in reality reject the Christian gospel. Is there a Christian reply to the deep problems of the alternative religion which presents itself in the West? The Christian message must be in total and encompassing. Science which is practiced from the perspective of faith should therefore, among others, have the following aspects: A broad perspective in acknowledging God in whom the freedom in Christ is the true freedom for life; and also a respect for humanity in the practice of science from the perspective that God is the One who in Jesus Christ gives true life. There must also be an eschatological perspective. Reformational renewal of the community and especially in science requires the acknowledgement of Jesus Christ's life-changing influence and rule. These aspects will receive attention in the article.

\section{Inleiding}

Die westerse beskawing is in sekere opsigte op die Christelike boodskap gebou. Sedert die invloed van die Christelike evangelie wat deur die apostel Paulus verkondig is en in westerse lande deur die uitbreiding van hierdie evangelie beslag gekry het, is die Christelike grondslag van die westerse samelewing as belangrik beskou. Dit is duidelik dat die veelkleurigheid van die Christelike boodskap nie eenduidig is nie en dat verskeie elemente daarvan op verskillende en uiteenlopende wyse ' $n$ neerslag in die westerse samelewing gevind het. Christelike oortuigings het dus ook wel in die westerse beskawing 'n neerslag gevind. Daar was tye van eb en vloed en insigte is somstyds bybels begrond en dan weer misken. Dat daar wel bepaalde Christelike invloed was, kan nie ontken word nie. Hierdie grondslag is egter nie sonder probleme so aanvaar nie en verskillende aspekte het deur die jare hierdie invloed weggekalwe of geminimaliseer. Die aanvanklike optimisme van 'n Christelike bestel ná die Konstantynse oorname, het plek gemaak vir 'n diepe pessimisme van die kerklike bestel in die Middeleeue, wat deur die Rooms-Katolisisme beheers is. Met die Reformasie het daar 'n nuwe verwagting gekom wat die beklemtoning van die Christelike grondslag van die samelewing weer op die voorgrond geplaas het. Die optimisme van die groot sendingeeu het tot ongeveer 1910 geheers en voortgeduur ook gedurende die sendingkonferensie te Edinburgh. Hier is die westerse samelewing as 'n herout van die Christelike boodskap beskou. Hierdie optimisme het egter gedurende en ná die Eerste en Tweede Wêreldoorloë vir diepe pessimisme plek gemaak. Ten spyte van hierdie agtergrond is dit nog steeds duidelik dat die Christelike grondslag van die westerse samelewing en die Christelike invloed daarop nie onderskat kan word nie.

Christelike beginsels soos die klem op die erkenning van God in Jesus Christus, die opgestane Here, respek vir God, naasteliefde, medemenslikheid, geregtigheid en gelykheid voor die reg het 
'n diepgaande invloed op die westerse samelewing gehad. Daar kan verwys word na die demokratiese regeerstelsel, die ontwikkeling van 'n vrye regbank en die erkenning van die waarde van die mens asook die erkenning van God. In die sestigerjare van die vorige eeu het daar egter ' $n$ verskuiwing plaasgevind vanaf 'n oortuiging dat die westerse samelewing op die Christelike boodskap gegrondves is, tot die opkoms van die Sekularisme. In Wes-Europa het kerke leeggeloop en het die bevraagtekening van die Christelike evangelie al hoe sterker na vore getree. Uit verskeie oorde was daar vrae oor die begronding van die westerse samelewing op die Christelike boodskap. Die erkenning dat die Woord van God die beginsels vir die lewe gee waaraan almal gebonde is en dat vryheid in God gevind moet word, is in baie opsigte deur die westerse soeke na 'n nuwe wetenskapsideaal en 'n totale vryheidsideaal agtergelaat. Daar is opnuut na die betekenis van verskillende aspekte van die samelewing gevra.

\section{Wetenskapsbeoefening}

Die soeke na neutraliteit in die wetenskapsbeskouing is sedert die Aufklärung sterk beklemtoon. Alhoewel dit baie duidelik was dat hierdie neutraliteit nie deurgaans moontlik is nie, word dit steeds in verskillende gebiede nagejaag en as voorbeeld voorgehou. Die modernistiese uitgangspunt bevestig dat die outonome mens wel deur rasionaliteit neutrale wetenskap kan beoefen. Die neutrale beginsel moet as die grondslag van die wetenskapsbeoefening beskou word. Hierdie uitgangspunt beklemtoon dit dat die filosofiese en religieuse uitgangspunte as ' $t$ ware opgeskort moet word om suiwer wetenskap te beoefen. Die mens agter die wetenskap moet neutraal wees. Die opskorting van die eie uitgangspunte sal hiervolgens tot algemeen-geldende gevolgtrekkings lei. Omdat dit ook vanuit hierdie standpunt nie seker is of God bestaan nie, is die opskorting en die verskuiwing van God uit die openbare sfeer nodig. Hiervolgens sal suiwer wetenskap dus nie terselfdertyd diepgaande Christelik kan wees nie.

In sommige kringe word neutraliteit in wetenskapsbeoefening opnuut nagejaag. Vir die voorstanders van hierdie posisie is die uitgangspunt dat God by die wetenskapsbeoefening betrek kan word, hoogs onaanvaarbaar. Die uitgangspunt is daarom om die wetenskap vanuit 'n standpunt te beoefen wat radikaal van enige beïnvloeding vry is. Dat dit as onhaalbaar bewys is, word nie aanvaar nie. Dawkins (2006:137 e.v., 188-189) se beskouings is in hierdie verband belangrik. Van God moet heeltemal afskeid geneem word. Suiwer wetenskap staan op sy eie voete en moet volgens Dawkins nie deur enige geloof in God vertroebel word nie. Die wetenskap het 'n eie unieke grondslag en mag nie deur die geloof in God bepaal word nie. Dawkins (2006:189) kom dus tot die slotsom dat '... the factual premise of religion - the God hypothesis - is untenable. God almost certainly does not exist.'

Dooyeweerd (2012) het aangetoon dat die grondmotiewe van die denke beduidend inwerk op die belissings wat in die uitwerk van die oortuigings geneem word. In hierdie verband het hy die ideale paar van die wetenskapsideaal en die vryheidsideaal van die westerse samelewing gepostuleeer. Dooyweerd (2012) skryf:
Unquestionably, the freedom motive was humanism's deeper driving force. This motive embodied itself in the modern ideal of the personality, the cult of the human person understood as an end in itself. Freed from all faith in given authority, human personality attempted to establish the law for itself in complete autonomy and according to its own rational standards. The new view of nature itself was rooted in the freedom motive. It was not inspired by the Greek motive of form and matter. It also withdrew itself from both the groundmotive of divine revelation, that of creation, fall and redemption through Jesus Christ, and the Roman Catholic groundmotive of nature and grace (supranature). Modern humanity saw 'nature' as unrelated to and uninfluenced by 'supranatural' powers; 'nature' was conceived of as reality within space and time to be completely controlled by natural science and technology. It was believed that human freedom would achieve its highest expression in its mastery over nature. It was this belief that called forth the classical humanistic science ideal, which declared that the natural-scientific method could analyze and reconstruct reality as a completely determined and closed chain of cause and effect. This assumption was the basis of the classical humanistic motive of nature. (bl. 170)

In die ontwikkeling van hierdie oortuigings het die Weste egter juis die plek van God begin bevraagteken. Die vraag wat nou gevra word, is of God werklik nog 'n plek in die samelewing het. Indien die Christelike ideaal agtergelaat word en indien daar in die westerse samelewing na ' $n$ ander ideaal gestrewe word, is die vraag of daar nie inderdaad 'n verskuiwing na 'n alternatiewe godsdiens plaasgevind het nie. In sodanige alternatiewe godsdiens speel die gode en/of beginsels wel 'n rol, maar nie die God van die Bybel nie. Daar moet dus gevra word na die godsdiens en grondslag van die westerse samelewing. Die vraag is verder ook hoe dit die samelewing in die algemeen beïnvloed en wat die invloed daarvan is wanneer hierdie nuwe godsdiens van toepassing gemaak word op die wyse waarop mense daarmee omgaan ten opsigte van hulle totale lewensvisie. Die kern wat hanteer sal word, is die vraag op watter wyse die drie-enige God in ' $n$ totale lewensvisie erken sal moet word.

\section{Die opkoms van 'n alternatiewe godsdiens}

Die Sekularisme, die Humanisme en die Paganisme is merkers wat die verskuiwing kan aanstip wat in die westerse samelewing plaasgevind het. Die Sekularisme dui op 'n lewensingesteldheid waarin daar vir God nie plek is nie. Die Humanisme dui daarop dat die mens die sentrale persoon in hierdie verandering is en die Paganisme dui op 'n alternatiewe soort godsdiens waarin daar weinig plek vir die God van die Bybel is.

\section{Die Sekularisme}

Wat die Sekularisme betref, is dit duidelik dat dit 'n radikale invloed op die Europese samelewing gehad het. Waar die kerke voor die Tweede Wêreldoorlog nog vol was en selfs ook ná die oorlog heelwat lidmate gehad het, was daar 'n groeiende groep lidmate wat van die kerk af wegbeweeg het. Hulle het juis van die kerk afskeid geneem omdat hulle van mening was dat God eintlik nie meer in die situasie waarin hulle verkeer, iets te sê het nie. God is uit die samelewing en 
die openbare lewe weggeskuif. In die Middeleeue was God nog sentraal in die hele gemeenskap - dit was gekenmerk deur die kerktoring wat uitgestyg en bo die hele dorp uitgetroon het. Na die Tweede Wêreldoorlog het hierdie gedagte dat God werklik nog iets vir die gemeenskap te sê het, van al hoe minder belang geword. Smith (2010:7) bevraagteken die standpunt dat die afname in kerkbywoning en die betrokkenheid by geestelike sake daarop dui dat afskeid geneem is van die Christelike oortuigings in die Weste. Hy is van mening dat Sekularisme in die Weste nie beteken dat die geloof in Christus verloën word en dat God nie meer van belang geag word nie. Die vier argumente wat hy aanvoer, is dat die Christendom nog altyd meervoudig was en sy vorm deur die eeue baie aangepas en verander het. Tweedens het die middeleeuse Christendom en die huidige vorms van die Christendom meer ooreenkomste as verskille. Met die Verligting (Aufklärung) het derdens die breuk tussen die Christelike dogma en die Christelike etiek gekom. Die etiek wat oorgebly het, is op 'n Christelike wyse beoefen. Laastens was die Victoriaanse tydperk 'n unieke, maar geensins normale tydperk vir die kerk nie. Verskeie argumente kan egter teen Smith se standpunt ingebring word. Om bloot op 'n sensusvorm aan te dui dat jy Christen is, maar om dan die metafisiese in jou lewe te misken, beteken nie dat Sekularisme nie diepgaande deel van jou lewe is nie. Verskillende vorms van die Christendom het altyd die radikale erkenning van God as uitgangspunt gehad: die middeleeuse mens het erken dat God die totale beheerser van alle lewensvorme is; die breuk tussen dogma en etiek is veel dieper as wat Smith erken en in gemeenskappe in Afrika en die Ooste is daar tans nog 'n erkenning van God wat nie in die sekulêre Weste voorkom nie.

Degenaar (1967:73) wys daarop dat die woord sekularisasie hoofsaaklik gebruik word om die proses aan te dui waarin wegbeweeg word van 'n religieuse en metafisiese wêreld na 'n toestand van groter selfstandigheid vir mense en die verstaan van hulleself en die wêreld. Degenaar toon verder aan dat hierdie 'n omvattende proses is wat beskryf kan word as die proses van vrymaking. Hierdie vrymaking speel sigself in die natuurwetenskappe af en daardeur verval die Godsbegrip in die wêreld. Degenaar (1967:73) argumenteer dat die Filosofie ook die proses van bevryding ken, deurdat die metafisies-gebonde denke sigself al hoe meer beperk tot denke wat binne die Eksistensialisme, die Fenomenologie en die analitiese filosofie onderskeidelik tydsgebonde, fenomeengebonde, taalgebonde en verifieerbaar is.

Van der Walt (1984) dui aan dat 'n bepaalde definisie van Sekularisme inderdaad beteken dat die mens God totaal uit sy gesigsveld uitskakel:

Sekularisme, uit die ateïstiese denkbeeld van drie eeue gebore, is 'n subjektivistiese, relativistiese en utilitaristiese lewensvisie asook die resultaat of toestand as gevolg daarvan - waarvolgens die sogenaamde mondige, vrye, selfstandige mens weens die besondere magte waaroor hy vandag sou beskik, die plek van die syns insiens oorbodig geworde God ingeneem het, sodat hy nou alleen uit, deur en tot hierdie in sigself geslote wêreld kan lewe. (b1 48)
Die gesekulariseerde gemeenskap wil God nie as die Skepper, Onderhouer en Beskermer van die werklikheid erken nie. Die mens se wetenskaplike oortuigings is genoegsaam om antwoorde te bied en daarom wil die mens self na verskillende antwoorde soek. God self moet eenkant toe geskuif word asook sy invloed op die wetenskap en op die mens se ontwikkeling. Die mens moet uiteindelik self probeer om met 'n antwoord vir elke unieke situasie vorendag te kom. Die Sekularisme het in die modernisme 'n bepaalde hoogtepunt bereik. Taylor (2007) skryf:

The notion of secularity I'm using here is radical, because it stands not only in contrast with a divine foundation for society, but with any idea of society as constituted in something which transcends contemporary common action. (bl. 192)

Geen vrae moet van buite aan die werklikheid gestel word nie. Slegs immanente vrae kan beantwoord word. Enige poging om in vakgebiede soos die Psigologie, die Regte of die Ekonomie na God te verwys, word afgewys. Die klassieke voorbeeld van hierdie beskouing is Dawkins (2006:31 e.v.) se aanval op die religie waarop McGrath en McGrath (2007:51) antwoord dat die Sekularisme self met hulle eie vooronderstellings nie van fundamentalistiese argumentasie loskom nie. God self het nie 'n invloed op hierdie terreine nie, is beweer, en die betrokkenheid van God het uiteindelik bloot 'n lastigheid geword wat weggewys word. Bush (1984) verduidelik dit soos volg:

Thus to be secular is to be given to the concerns of the present age, to lack a transcendent perception of reality, to belong to the present world as distinguished from the spiritual or eternal reality of God. Secular humanism is then the practice and advocacy of nontheistic humanism by legislators, judges, scientists, educators, writers, and entertainers. This powerful force of ideas is encountered virtually everywhere today. (bl. 6)

In die sogenaamde God-is-doodteologie is eweneens beweer dat die mens self los van God na antwoorde moet soek. 'n Bekende voorbeeld is dat persone wat in 'n vliegtuig klim baie eerder hulle vertroue in die loods moet stel as in God self wat sogenaamd beheer oor die vliegtuig sou uitoefen. Ook wat die landbou en ontwikkeling betref, is baie duidelik gestel dat mense nie van God afhanklik moet leef nie, maar hulle eie vermoëns asook die wyse waarop hulle by hierdie werklikheid betrokke is, moet gebruik om antwoorde te suggereer.

Met die opkoms van die Postmodernisme het die Sekularisme nuwe betekenis verkry. Relativering is nou die nuwe uitgangspunt. Alle aspekte van die samelewing moet vanuit die relatiwiteit van alles bedink word. Die meesterverhale (grand narratives) word prysgegee en nuwe beginsels word neergelê. Dit is veral die meesterverhaal van die Christelike oortuiging wat bevraagteken word. Sake soos die meesterverhaal van 'Skepping, sondeval en verlossing' word as agterhaal beskou. Janse van Rensburg $(2000: 8,9)$ toon aan hoedat die sentrale oortuigings van die miskenning van meesterverhale, die ontkenning van absolute waarhede en die uitgangspunt dat waarheid slegs in sekere kontekste waar kan wees, tot die ineenstorting van eenheid lei: 'The collapse of unity therefore stands for the postmodern rejection of a system 
of universally applicable truths and principles.' Lyotard, volgens Janse van Rensburg (2000:27), bevraagteken byvoorbeeld die bestaan van God juis omdat dit 'n onwrikbare waarheid sou vaslê. Mag moet ook afgebreek word en alhoewel die Christelike liefde positief beoordeel sou kon word, word mag die beginsel waarmee die Christendom sy aansprake bevestig en daarom is dit verwerplik. Dit was egter veral Derrida (2002) wat volgens Anidjar (2002) die begrip van die Abrahamitiese in die geloof beoordeel en aandui dat dit alle geloofsoortuigings bevraagteken:

The Abrahamic, in Derrida, is a silent, forgotten hyphen that constitutes the secret holding of links beween the personal and the political, between the political and the theological, whose porous boundaries are constantly violated. It inserts itself enigmatically and persistently in an unwritten and unreadable history ... 'Religion', as the Abrahamic, while we claim it as 'our own' can only disown us. (bl. 19, 20)

Derrida (2002) handhaaf die idee dat die taal van geloof self bevraagteken moet word. Die verwerping van die taal en die dekonstruksie daarvan moet dus tot ander interpretasies lei:

But is seems impossible to deny the possibility in whose name - thanks to which - the derived necessity (the authority or determinate belief) would be put in question, suspended, rejected or criticized, even deconstructed. One can not deny it, which means that the most one can do is to deny it. (bl. 93, 94)

In 'n sekere sin word hier van die uitgangspunte van die Modernisme wegbeweeg, maar die vaste oortuiging dat God die werklikheid bepaal, word eweneens agtergelaat (Veith 1994:42 e.v.). Klinghoffer (2005:62) stel dit soos volg: 'Let's face it: Secularism is a religion. Let's treat it as such.'

\section{Die Humanisme}

Sover dit die Humanisme aangaan, het die mens absoluut in die middelpunt kom staan. Mense self het die maatstaf van hulle bestaan geword. Die mens as middelpunt het die hoogste goed geword en alle benaderings tot die mens self word deur die gedagte gedra dat hierdie mens sentraal staan. Die hoogtepunt van die Humanisme is geleë in die hubris van die mens self waarin vir God of sy gebod geen plek is nie. Die etiek moet hier uiteindelik self tot die mense in hulle bestaan herlei word. Die mens is dus daartoe verbind om slegs vanuit elkeen se eie bestaan tot gevolgtrekkings te kom en rigtings aan te dui. Dit lei uiteindelik daartoe dat die mens self die hoogste goed word en dat alle beginsels afgelei moet word uit die feit dat hierdie mens die hoogste goed is. Die probleem is egter dat dit ook dikwels daartoe gelei het dat waar gevolgtrekkings gemaak, uitgangspunte ingeneem en standpunte gestel moet word, hierdie gevolgtrekkings, uitgangspunte en standpunt dikwels lynreg teenoor mekaar te staan kom. Dit gebeur omdat mense hulself telkemale in die problematiek vasloop dat die eie standpunt die hoogste goed is. Teenstrydighede in die werklikheid wat hulle nie kan verwerk nie, kan nie beantwoord word nie. Hierdie teenstrydighede lei daartoe dat die mens per slot van rekening geen antwoord op die groot vraag van die werklikheid het nie en nie antwoorde kan bied op die eksistensiële vrae wat gestel word nie, byvoorbeeld die vraag na die werklikheid van die dood in die mens se bestaan.
Strauss (1990:141) verwys na die opkoms van die humanistiese denke en die ontwikkelingsgang daarvan wat al in die vyftiende eeu na Christus na vore tree en waar die moderne nominalisme met die bybelse skeppingsgeloof afgereken het. Die gedagte was dat indien skepsele oor geen universele kant, geen ordelikheid beskik nie, dit vanself spreek dat die mens moeilik nog aan 'n universele, bepalende, begrensde skeppingswet kan vashou. Die mens sou dus gestroop van alle ordelikheid en ordebepaaldhede, slegs 'n chaotiese en struktuurlose menigvuldige ding in die konkrete individualiteit bly. Strauss toon aan dat die gebrek aan hierdie ordebepaling vrugbaar deur die rasionalistiese stromings van die moderne humanistiese wysbegeerte aangegryp is. Immanuel Kant het uiteindelik die uiterste rasionalistiese konsekwensie van die nominalisme getrek deur op die menslike verstand te dui wat ten diepste die wesenlike van die mens bepaal. Strauss dui aan dat die menslike verstand, volgens Kant, eintlik die aprioriese wetgewer van die natuur word. Die verstand skep nie net sy eie wette-apriorie uit die natuur nie, maar skryf dit selfs aan die natuur voor. Strauss (1990:141) wys ook daarop dat die irrasionalistiese kant van die nominalisme' $n$ vrugbare teelaarde gebied het vir die irrasionalistiese stromings in die moderne wysbegeerte, wat in die sogenaamde na-Kantiaanse vryheidsidealisme verrys het. Voorbeelde hiervan is die ideologie van die unieke volksiel wat in elke bo-individuele volksorganisme verskyn (opgevolg deur die Nazisme) en die opkoms van die eksistensie-filosofie, die pragmatisme, die personalisme, die neo-Marxisme (uitgesonder Habermas) en die historisme in die eksistensieel-fenomenologiese denke. Hierin word telkens op die een of ander wyse alle eer aan die uniek-individuele (kontingente) gebring.

\section{Strauss (1978a) skryf oor die humanistiese vryheidsideaal:}

In laaste instansie is die humanistiese vryheidsideaal self 'n ombouing en verwêreldliking (sekularisering) van die vryheidsopvatting van die Bybel: in stede daarvan dat die mens sy vryheid in Christus vind wat hom verlos van die sondeslawerny en vrymaak tot gehoorsaamheid aan die Godgestelde skeppingsbeginsel vir sy ganse lewe, word die mens vergoddelik tot selfwetgewer, sodat egte vryheid vir die humanisme slegs kan bestaan wanneer die mens wette gehoorsaam wat hy vir homself geskep het. (bl. 9)

Dooyweerd (2012) skryf in hierdie verband:

The humanistic personality ideal thus deepened and broadened itself as a community ideal. In its irrationalistic turn it simultaneously acquired a universalistic character. Freedom and autonomy were conceived of as the freedom and autonomy of the individual community of persons. This universalism is the ideology of community. (bl. 178)

Met die opkoms van die Postmodernisme word die mens welliswaar nie as God beskou nie, maar die sentrale benadering behou die mens as die middelpunt in die wetenskaplike denke (Veith 1994:80 e.v.).

\section{Paganisme}

Die derde saak wat na vore kom, is Paganisme. Dit blyk in 'n sekere sin teenstrydig met die Sekularisme en die Humanisme te wees, maar dit dui tog daarop dat die mens 
in die nuwe westerse samelewing uiteindelik ook rondom die hele kwessie van die Paganisme daartoe verbind is om alternatiewe gode, maar almal met kleinletters geskryf, in die eie werklikheid in te neem. Dus: sekularisties - vir God is daar geen plek nie; en humanisties - die mens staan in die middelpunt. Hierdie mens wat nou in die middelpunt staan, wil die eie werklikheid sinvol benader. In 'n poging om aan die werklikheid sin te gee, probeer die mens hulle eie gode skep. Morris (2006:274) toon aan hoedat daar ten opsigte van godsdienstige oortuigings ' $n$ bewustelike toename in preChristelike paganistiese oortuigings in Wes-Europa en die VSA voorkom. Morris (2006) skryf:

Whether or not Neopaganism is simply an 'invented' or 'imagined' tradition, part of reaction against Christianity and the vicissitudes of capitalist 'modernity', or whether it is a 'survival' or 'revival' of pre-Christian beliefs and rituals has long been the subject of debate. Scholars and adherents within the Neopagan movement, however, tend to stress that it is not the same 'New Age fad' but the reaffirmation of a religious tradition that goes back to antiquity; it is thus something of 'revivalist' movement. (bl. 274)

Hierdie paganistiese gode voed religieuse oortuigings wat teruggaan na historiese paganistiese benaderings. Dit is vergelykbaar met die gode van die ou Griekse en Romeinse tyd waar die mens eintlik 'n antwoord op die onverklaarbaarhede van die werklikheid probeer vind deur projeksies te maak wat dan bepalend vir hulle bestaan is. Hierdie gode word deur die mens self geskep. Henry (1988:16) verwys na die wyse waarop die Christelike evangelie deur die opkoms van 'n totale paganistiese gesindheid bedreig word. Nie alleen word op verskeie terreine teruggegryp na paganistiese oortuigings nie, maar daar word ook direk teen die Christelike evangelie opgetree. Die oproep tot 'n nuwe mens word dikwels nie vanuit die evangelie gedoen nie, maar volgens Henry, vanuit 'n benadering van menslike gode. Die mens wend pogings aan om hierdie gode uit hulle eie bestaan tot godheid te bevorder en hulle ook self sodanig te formuleer. Op verskillende wyses formuleer die mens verskillende aspekte van die eie bestaan en hierdie gode wat dan ' $n$ invloed op die mens uitoefen, is dan die nuwe godsdiens van die vrye mens. Hierdie gode sluit in die uitwasse van 'n geloof in ekonomiese groei, diereregte wat op buitensporige wyse toegepas word, die oordrewe vorms van medemenslikheid en vryheid wat nie in ag neem dat die mens ook verantwoordelikhede het nie, asook die uitwasse van die materialisme. Menseregte wat nie met verantwoordelikhede gepaard gaan nie, word ook uitgelig. In hierdie verband is dit dus betekenisvol dat die mens deur die Sekularisme en die Humanisme beweeg tot by 'n standpunt waar die mens uiteindelik hulle eie gode formuleer.

Taylor (2007:269) toon aan dat die ongeloof en Humanisme juis teen die agtergrond van die religie hulle standpunt inneem. Hulle kom nooit heeltemal vry van die diepgaande relasie tot geloof nie, alhoewel hulle juis daarteen stry.

In die Postmodernisme is die mens self nie god nie. Die Postmodernisme wys die menslike goddelikheid van die hand en sê dat hulle in hierdie opsig nie met Modernisme saamstem nie. Wat egter wel van belang is, is dat die mens in die Postmodernisme steeds hulle eie gode moet vorm. Dit is waarom die Modernisme en die Postmodernisme nie so ver van mekaar af staan nie. Al erken die Postmodernisme dat die mens nie god is nie, skep die mens vir sigself 'n verskeidenheid gode en daardie verskeidenheid gode moet binne die mens se werklikheid verstaan word. Hierdie nuwe godsdiens van die postmodernistiese mens is ' $n$ godsdiens wat diep in die werklikheid van die gemeenskap insny. In hierdie verband kan weereens na Derrida (2002:70) verwys word. Sy benadering tot die Abrahamitiese lei uiteindelik tot 'n miskenning van die Christelike evangelie.

\section{Die aanklag teen die Christendom}

In die eerste plek moet aangedui word dat daar wel groot krisisse in die verskillende standpunte binne die Christelike wêreld is. Die Christendom het in 'n sekere sin dikwels nie positief op die uitdagings van die tyd gereageer nie en die gevolge van hierdie optrede is ook deur sommige mense in die kritiek teen die Christendom aangegryp. Die Christendom het inderdaad nie daarin geslaag om op so 'n wyse op die werklikheid in te werk dat dit vir die meeste mense en gemeenskappe heilbrengend is nie. Verwoestende oorloë is in die naam van God geveg en die wetenskapsbeskouings was soms aweregs soos die hantering van Galileo Galilei as 'n tipiese voorbeeld dien. Die kerk het soms in die naam van God beheer oor gemeenskappe probeer uitoefen en dit het nie noodwendig heil gebring nie. In hierdie verband skryf Van der Walt (1984):

Indien die Christene die beeld van hulle God beter vertoon het, sou dit moontlik nie vir hierdie mense nodig gewees het om dié God saam met die Christendom te verwerp nie. (bl. 44)

Bevooroordeling het dikwels mense se lewens bepaal en in die wetenskap is die vryheid van denke dikwels ingeperk. Die nuwe godsdiens, die Sekuralisme, die Humanisme en die paganistiese godsdiens, is nietemin ' $n$ afvallige antwoord op die problematiek soos dit binne die Christendom ontwikkel het. Is daar wel 'n Christelike antwoord op die problematiek van die Weste?

\section{'n Christelike benadering Christelike grondslae}

Die oortuiging dat daar wel 'n Christelike standpunt ingeneem kan word en dat die uniekheid van Jesus Christus erken moet word, is volgens die sogenaamde Nuwe Hervormers (vgl Craffert 2002:172-175) verkeerd bewys. Volgens hierdie standpunt is dit nie moontlik om vanuit 'n diep Christelike oortuiging ' $n$ aanduiding van die verhouding met God te gee nie. God self kan slegs maar in die privaatheid van die mens se eie bediening beleef word, maar nie in die openbare lewe waar mense met die werklikheid rondom hulle te doen het nie.

Ten opsigte van die wetenskaps- en vryheidsideaal word dit goed geïllustreer deur die feit dat ten opsigte van die wetenskapsideaal, die neutraliteit van die wetenskap sterker na vore kom. Volgens hierdie standpunt bestaan daar wel 
'n neutrale wetenskapsbeskouing wat nagejaag moet word. Ten spyte van die feit dat hierdie wetenskapsbeskouing neutraliteit voorstaan, word hierdie beskouing telkemale self gevul met die gode van die nuwe werklikheid, te wete die bepaalde wetenskapsideaal. Hierdie beskouing staan ook onverdraagsaam teenoor diegene wat 'n ander standpunt huldig en wat ten opsigte van die wetenskapsideaal geloofstandpunte sou inneem.

Van der Walt (1999a:4) verwys na die Christelike geloof as 'n reformatoriese, wêreldveranderende godsdiens wat reeds by sy ontstaan 'n diepgaande invloed op die gemeenskap uitgeoefen het. Hy wys ook verder daarop dat die westerse Christendom in die tweede millennium daartoe bygedra het dat die Weste verchristelik is, maar aan die ander kant het daar ook 'n verwestering van die Christendom plaasgevind. Die positiewe wat hieruit voortkom, is die openheid van die Christelike wêreld vir verandering, die kritiese gees van die Verligting en politieke vryheid, demokrasie en menseregte. Daar is egter ook minder positiewe gevolge soos die feit dat die alledaagse, sogenaamde sekulêre lewe van die heerskappy van die kerk bevry is. Dit het daartoe gelei dat alle lewensterreine, byvoorbeeld die politiek en die ekonomie, van die Christelike geloof losgemaak is. Dit het tot negatiewe sekularisasie gelei.

Die uitdagings in die derde millennium word deur Van der Walt (1999a:7) uitgelig. Hy wys daarop dat Christene ernstig moet besin oor dit wat tipies Westers is teenoor wat outentiek Bybels is en dat daar 'n verskil moet kom tussen die Westerse en die outentiek Bybelse. Daarmee saam sal dit noodsaaklik wees om die verskillende tradisies wat in die Weste geamalgameer is, te probeer onderskei sodat bepaal kan word dit wat eintlik die erfenis van die verwestering van die Christendom is en nie soseer die erfenis van die Christendom self nie.

Verder dui Van der Walt (1999a:587) ook op die feit dat die Christelike wetenskapsbeoefening deur sy getrouheid aan die ware God gekwalifiseer word. 'Die verskil of onderskeid is dus nie 'n voorwaarde vir 'n wetenskap om Christelik te wees nie, maar dikwels eerder die gevolg van 'n geloofsgetroue (Christelike) wetenskap.' Van der Walt (1999a:588) stel dit baie duidelik dat 'n werklik Christelike wetenskapsbeoefening nie bloot tussen die bestes onder die bestaande wetenskaplike teorieë moet kies nie. Dit moet inderdaad probeer om die evangelie en die wetenskap op so 'n wyse te gehoorsaam dat 'n nuwe aanpak, 'n oorspronklik Christelike alternatief, begin vorm aanneem.

Hy sluit af (Van der Walt 1999a):

- Christelike wetenskapsbeoefening beteken voortdurende stryd teen die verleiding van verkeerde beskouinge (soos sintese en sekularisme), maar dit beteken ook

- die positiewe uitwerk van 'n eie visie. (bl. 588)

Van der Walt (1999a) verduidelik verder:

'n Christendom met diepgang en breedte van perspektief kan alleen gevind word indien ons dit sien teen die agtergrond van die feit dat godsdiens (ook die Christelike geloof) met al drie (God, wet en skepping) te make het. Godsdiens is, soos die woord duidelik sê, diens aan God. Maar ons dien God in sy skepping, sy hele skepping (waarvan ons as mense deel is). En hierdie diens aan God moet volgens sy wil geskied - anders is dit nie ware godsdiens nie! (bl. 601)

Daar kan inderdaad saamgestem word dat die Christelike boodskap 'n volledige en omvattende saak behoort te wees. Die problematiek bly egter dat die Christendom die onvermoë vertoon om juis dit te bereik. Daarom word juis aangedui dat Van der Walt té optimisties oor die moontlikhede van die ryk van God binne hierdie wêreld is. Van de Beek (2008:221-232) se beskouing hierteenoor is meer pessimisties. Hy gaan van die standpunt uit dat die wêreld nie ons woning is nie. Hierdie wêreld is onderhewig aan die verganklikheid. God se vernuwende wêreld is aan die kom, maar tans is ons nog onderworpe aan die verganklikheid. Van der Walt (1999a:601 e.v.) toon egter aan dat die vernuwende werk van Christus en die Heilige Gees erken moet word.

Strauss (1990:116) beklemtoon op sy beurt dat 'n nuwe tydperk aangebreek het toe die voorhangsel in die tempel geskeur het. Deur Christus se kruisiging het 'n nuwe bestel na vore getree wat daarop dui dat deur die dood van Christus, die weg tot God geopen is vir almal wat deur God in Christus uitverkies is. Die nuwe bedeling impliseer dat die heerlikheid van God op alle lewensterreine gedien moet word noudat die voorhangsel geskeur het. Strauss (1990:117) dui aan dat soos Israel van ouds in alle lewensgeledinge 'n godsgehoorsame lewe moes lei, die nuwe volk van God, inderdaad die nuwe Israel, binne die lewensomvattende diens aan God binne sy koninkryk staan - of hulle nou ook al eet of drink, of enigiets anders doen (vgl. 1 Kor 10:31). Die Ou-Testamentiese voorhangselbedeling is dus nou volgens hom (Strauss 1990:117) agterhaal, want in Christus is die volle lewe, waar God se Gees ook al werksaam is, geheilig, afgesonder vir en toegewy aan God - God wat in Christus en deur die Heilige Gees teenwoordig is. Dit impliseer dat ons volgens Strauss álle dae van die week, álle plekke op aarde, met ál tien tiendes van ons inkomste en in álle lewensvorms (nie slegs in die kerk as instituut nie) tot eer van God in sy koninkryksdiens moet lééf.

Wat die Postmodernisme betref, lewer Janse van Rensburg (2000) 'n besondere bydrae. Hy is van mening dat die uitgangspunte van die Postmodernisme, naamlik die ineenstorting van eenheid en die verwerping van die abolsute waarheid noodwendig tot etiese relativisme moet lei. Veral die Christelike etiek word verwerp:

Efforts to prove that postmodern epistemologies and Christian ethical norms are compatbile simply cannot succeed because of the opposing and excluding convictions that both represent. Efforts to reconcile these opposing epistemologies inevitably end in a sea of contradictions. (Janse van Rensburg 2000:74)

\section{Christelike vryheid}

Die tweede saak wat na vore kom, is die vryheidsideaal. Die alternatiewe humanistiese, paganistiese, sekularistiese westerse godsdiens wil die vryheidsideaal sterk beklemtoon. Terwyl dit gedoen word, word die menseverhoudings egter 
op 'n nuwe manier gestruktureer. As gevolg hiervan is die mens nie bereid om die gesag van die goddelike oorsprong te erken nie. Die vryheidsideaal word absoluut en die mens self, met 'n eie nuwe godsdiens, bepaal wat hierdie vryheidsideaal is en hoe dit verstaan moet word. Sodoende word eintlik wegbeweeg van die genadige ingryping van God in mense se lewens en die veranderende en helpende verandering wat God vir mense bring. Dit alles lei tot 'n nuwe vraag: Hoe kan 'n Christelike oortuiging en 'n Christelike standpunt te midde van hierdie verskillende filosofiese en godsdienstige standpunte ingeneem word? Op watter wyse kan 'n Christelike standpunt gestel word en hoe lyk sodanige Christelike standpunt?

\section{'n Christelike lewens-en wêreld- beskouing is bepalend vir die mens Grondslae van die Christelike lewens-en wêreldbeskouing}

In die woorde van Van der Walt (2003:54), is 'n diepgaande Christelike wêreldbeskouing wel noodsaaklik. Dit moet ook in die hantering van die wetenskaps- en die vryheidsideaal uitmond. Hierdie diepgaande oortuiging moet uiteindelik daartoe lei dat die mens kan verstaan hoedat die verskillende aspekte van die verskillende dele van die samelewing tot Christus teruggebring kan word. In verband hiermee waarsku Van der Walt uitdruklik teen 'n dualistiese Christendom, naamlik 'n Christendom waar God aan die een kant erken word, maar waar aan die ander kant 'n samelewing gebou word wat van Maandag tot Saterdag los van God bestaan. Van der Walt (2003:54) wys daarop dat daar in Afrika 'n dualistiese Christendom gevestig is. Die openbare en die private geloof en die kerk asook die sekulêre of die openbare terrein is van mekaar geskei. Hierdie dualisme beteken dat die invloed van die Christendom op die hele lewe agtergelaat is. 'n Liberale, humanistiese vorm van dualisme wil die politieke en sosiale lewe van die Christen van die transformerende invloed van die geloof in Christus skei. Van der Walt (2003) verwys na die volgende oplossing:

To overcome these dualisms Christians should distinguish between the good and evil aspects of creation and culture. We have to rediscover the biblical doctrines of creation, fall and redemption; all is good by creation; all is misdirected by the fall into sin; and all can be redirected by redemption in Christ. (bl. 55)

Van der Walt (2003:508) wys daarop dat die Christendom in baie opsigte nie 'n werklike invloed op die samelewing het nie en dat die rede hiervoor dikwels geleë is in die feit dat die Christendom nie 'n diepgaande, breë en geïnspireerde Christelike wêreldbeskouing daarop nahou nie. Volgens Van der Walt is dit nie genoegsaam om 'n wedergebore Christen te wees en gereeld kerk toe te gaan nie. Ons oë moet oopgemaak word vir 'n breër visie hoe om God in alle aspekte van ons lewe in te sluit en te dien. Al sou daar versigtig omgegaan moet word met die gedagte dat hierdie wêreld reeds totaal nuut kan word - God sal self die vernuwing in die herstel bring - is dit tog belangrik dat die tekens van God se koningkryk nou reeds opgerig moet word. Dit sal steeds in gebrokenheid geskied, maar met verwagting op die nuwe wat God bring.

\section{Dualisme deurbreek}

Hierdie dualisme moet deurbreek word. Die mens moet opgeroep word om voortdurend in alle aspekte van al die menslike verbande in afhanklikheid van God te lewe. Die werklikheid wat God daar stel, is die totale werklikheid. Dit beteken dus ook dat 'n mens in die wetenskapsbeskouing waarlik God sal erken en so voor God sal lewe dat alle aspekte van jou lewe daardeur geraak word. Dit mag nooit tot ' $n$ verenging van die wetenskaplike oefening lei nie, maar moet juis tot ' $n$ groter verruiming lei waardeur verskillende aspekte van die wetenskap in sy volheid ondersoek kan word om tot 'n nuwe gedagte te lei.

'n Ware Christelike lewens-en wêreldbeskouing wat ook die mens se bestaan beïnvloed, is dus baie belangrik. In al die verskillende verbande beteken dit dat die mens weer opnuut moet soek na die betekenisvolle verhouding waarin God erken word. Van der Walt (2008:166) toon aan dat 'n reformatoriese lewensvisie wat alle aspekte omvat, juis die dualisme deurbreek. Dit is moontlik omdat dit op God se openbaring begrond is, naamlik die Skrif en die skeppingsopenbaring en omdat dit God se wette vir die verskillende lewensterreine bekendstel. Hy (Van der Walt 2008:167) sluit af met die volgende stelling: 'Verlossing staan dus nie teenoor, langs of bokant die skepping nie, maar is bedoel om die skepping te herstel'.

\section{Wetenskap vanuit 'n geloofsperspektief}

Neutraliteit in wetenskapsbeoefening is onhaalbaar, omdat daar telkemale wel standpunte ingeneem moet word om wetenskaplike beginsels daar te stel (vgl. Dooyeweerd 2012). Hoe moet die wetenskap dan vanuit 'n geloofsperspektief beoefen word? Moet die wetenskap ingeperk word om die vryheid wat dit sonder sodanige perspektief sou ondervind, prys te gee? Onder bepaalde omstandighede kan dit wel beperkend op die wetenskap inwerk. Dit gebeur wanneer die uitgangspunt is dat die geloofsperspektief die vrye vloei van inligting en die oorweging van inligting beperk, of waar die filosofiese uitgangspunt eerlike gevolgtrekkings inperk deurdat die waarneming daardeur verkeerdelik geïnterpreteer word om die uitgangspunte te pas. Wanneer die geloofsperspektief egter die grondslae van die wetenskapsbeoefening bepaal, word die ruimte vir 'n oop perspektief wel neergelê. Dan kan die wetenskap juis in ware vryheid beoefen word.

\section{Strauss (1973) skryf:}

Die resultate van die transendentale kritiek, nl. dat alle teoretiese denke 'n transendentale grondidee veronderstel wat steeds gewortel is in 'n bepaalde religieuse grondmotief, bly steeds feilbaar vanweë die sonde wat in hierdie bedeling nog in die hart van elke verloste Christen aanwesig is. In soverre die Bybelse uitgangspunt van ' $n$ radikaal-Christelike transendentale kritiek egter ' $n$ bevrydende wysgerige perspektief moontlik maak wat die immanensie-standpunt selfs konfronteer met die onhoudbaarheid en innerlik-antinomiese karakter daarvan, is geen 'natuurlike teologiese' bekeringswerk verrig nie, maar is slegs in Christelike-wysgerige sin getuienis gelewer van die 
bevrydende krag van Gods Woord - 'n getuienis wat weliswaar in religieuse sin appelleer op die hart van die nie-Christen denker, maar wat slegs deur die toedoen van Gods lewendmakende Gees 'n hartsverandering, 'n bekering teweeg kan bring. (bl. 157)

Strauss (1973:163) skryf verder dat mense hulleself slegs in die sentrale religieuse kennis wat deur God gewerk word en wat tot bekering lei, volledig op God kan rig. Die mens moet daarvan bewus wees dat hulle dit slegs gelowig kan ontvang en in hulle sondige subjektiwiteit niks het om aan te bied nie. Eers met so 'n gesindheid sou die mens in 'n radikaal-bybelse sin die sinsverskeidenheid waaraan hulle in die tydelike lewe deel het, integraal in die liefdediens met die hele hart op God kon betrek.

\section{Uitgangspunte in 'n Christelike oortuiging}

Heyns (1978:276) beklemtoon dat die koninkryk van God deur Christus, wat as koning verheerlik word, ook in sy drievoudige amp in hierdie werklikheid inbreek. In hierdie sin verwys Heyns na sekere dimensies wat binne die koninkryk van God na vore kom sodat die hele lewe aan God gehoorsaam gemaak moet word. Dit word bepaal deur die Trinitariese dimensie, naamlik die Vader vestig die koninkryk en vorm die diepste grond vir die koninkryk; in die Christologiese dimensie neem die Seun die sentrale plek in die koninkryk in en die koms van die Seun impliseer die koms van die koninkryk; derdens dui die pneumatologiese dimensie daarop dat die Heilige Gees die beginsel en die krag wat in Jesus werksaam is tot aan die einde van die Messiaanse ampsvervulling bevestig het. Volgens Heyns (1978:280) dui die dinamiese dimensie aan dat die koninkryk wat naby gekom het nie 'n statiese onbeweeglike kant-en-klaar werklikheid is nie, maar ' $n$ gebeure wat in die werklikheid inbreek en deur die werklikheid vernuwing bring.

\section{Die verruimende perspektief van die erkenning van God}

Dit is nie aanvaarbaar om God uit die openbare sfeer weg te dryf, so asof dit in elk geval moontlik is nie. God eis sy reg in die hele gemeenskap op. Die wetenskaplike sfeer kan nie sonder God bestaan nie. Hy het die reg op alle menslike aktiwiteite. Daar moet 'n verruimde perspektief op God se heerskappy kom. Die wonder van die heerskappy van God bestaan in sy regering oor alle dinge. Dit moet egter die volheid van God se genadige ingryping in die mens se situasie veronderstel.

\section{Strauss (1978b) stel dit soos volg:}

Vanuit hierdie hoek gesien kan ons sê dat die verbondsgeskiedenis van Israel en die Koninkryksperspektief van die Nuwe Testament begrepe is binne die alsydige sin-dinamiek en ontsluiting van Gods skeppingsorde. Gevolglik kan daar nie omgekeerd uit die (eietyds gepositiveerde) verbondswoorde of ander Ou- en Nuwe-Testamentiese bepalings die gedifferensieerde beginsels vir ons ryk geskakeerde moderne lewe afgelei word nie. Die gemeenskaplike verwysingspunt bly steeds Gods universele skeppingsorde waarbinne Gods Woord-openbaring ook gegee is en sentraal religieus tot ons spreek.
Natuurlik is die religieuse harts-appél [sic] van die Bybel normerend in die sin van bepalend vir álle Christelike lewensuitinge van die mens (en nie slegs vir sy engere godsdienstige en geloofslewe nie). Dit is vanselfsprekend so omdat ons slegs in die Bybel in aanraking kom met die radikale (tot wortel-deurdringende) religieuse inhoud van die sentrale liefdesgebod, terwyl die feitlike inhoud van ons Christelike geloof slegs deur die Bybel in Christus aan ons besorg word. (bl. 83-84)

Dit is belangrik om vas te stel dat God die Een is wat erken moet word in die volle lewensbestaan. Elke aspek van die lewe moet onder die heerskappy van die drie-enige God gestel word. In Christus verkry die lewe nuwe sin en betekenis. Die lewe word ingevul met die oortuiging dat God die geskiedenis is en die toekoms beheer met die verwagte volledige koms van die koninkryk. Die Christelike lewensvisie is in hierdie verband beslissend:

Mashau (2009) beklemtoon die waarde van die Christelike lewensvisie:

Although the influence of secularism and pluralism has been devastating, it is my Reformed conviction that a missional church can bring about change in this regard by propagating a Christian worldview that seeks to penetrate every society with the lifegiving gospel of Jesus Christ who sovereignly reigns through his Word and Spirit. Jesus Christ is able to transform all cultures. He creates for his people a new Christian culture wherein peoples from diverse cultures and language groups become members of his one family - the family of God. (bl. 126)

God is besig om sy skepping na die voleinding te neem. Die werk van God is juis in die verlede sigbaar en sal ook in die toekoms sigbaar wees.

Berkhof (1973:232) skryf dat daar ten slotte ook gekyk moet word na die saak van skeppingsordenings of onderhoudingsordenings waardeur en waarbinne God sy werk volvoer. Daar moet daaraan gedink word in gesins-, staats-, arbeids- en gemeenskapsverband. Die onderlinge verhoudings van die werklikheid, meen Berkhof, skep 'n dinamiese konsep van die lewe en die samelewing.

'n Totaalvisie sluit egter die hele lewe van die mens in. Alle aktiwiteite moet die totaalvisie vertoon. Dit sluit ook die arbeid van die mens in.

Newbigin (1986:61) wys daarop dat wetenskaplikes al meer tot die besef kom dat hulle arbeid ook 'n etiese dimensie vertoon. Hy (Newbegin 1986) dui aan dat 'n dieper aspek noodsaaklik is:

But what is needed is something more, a framework of thought in which ethical considerations are not merely external regulators of the results of scientific work, but science is itself part of a whole way of understanding from which ethics cannot be separated, because all knowing is an activity of persons responsible to God and to one another. (bl. 61)

Belangrik is egter ook die oortuiging dat God die Skepper is en dat die Skepping nie 'n selfstandigheid buite om die geskapenheid vertoon nie. Deïsme moet dus afgewys word. 
Clouser (2006:64) toon aan dat, in plaas van die vergoddeliking van die werklikheid, daar inderdaad ruimte moet wees vir 'n verstaan van God wat alle reduksionisme teenwerk en teorieë beheer. Alleen in die verstaan van God se heerskappy oor die skepping, wat alle vergoddeliking uit die wetenskap weer, kan suiwer implikasies getrek word.

\section{Die vryheid in Christus as die ware vryheid tot die lewe}

In die wetenskap sal die soeke na die ware vryheid sentraal staan. Die vryheidsideaal dien die gemeenskap. Die ware vryheid is slegs in Christus te vind. Hy maak die deure na vryheid oop. Omdat Hy self die vryheid in God verpersoonlik, kan Hy ook vryheid aandui (be-teken). Wat is dan die inhoud van die vryheid in Christus? Christus se vryheid is die erkenning dat Hy alleen deur sy lewe, sterwe en opstanding vir die in-sonde-gevalle en sondige mens nuwe lewe skep. Die wesenlike van die vryheid moet in die oorwinning oor die sonde gevind word. Christus maak dit moontlik en verruim die horisonne van die wetenskap. In Christus verkry die skepping sy ware betekenis. Juis daarom is dit moontlik om die ware betekenis van die omgaan met die skepping in Christus se vernuwende werk te vind.

\section{Medemenslikheid in die wetenskapbeoefening vanuit die perspektief dat God die een is wat in Jesus Christus die ware lewe gee}

Ware medemenslikheid is onontbeerlik in die wetenskap. God gee die lewe en daardie lewe kan alleen in Jesus Christus tot volle betekenis kom. Die suiwer perspektief op medemenslikheid moet sonder twyfel gerig word deur die implikasies van die liefde wat uit Christus is. Hy gee die volle inhoud aan die begrip van liefde tot die naaste. Alle wetenskap het 'n etiese aspek en in Christus verkry hierdie etiese aspek nuwe betekenis. Christus eis met die liefdesgebod juis die liefde tot die naaste op.

\section{Nederigheid in die wetenskapbeoefening in die erkenning dat die mens ' $n$ in-sonde-gebroke wese is}

Wetenskapsbeoefening kan inderdaad tot volle hubris lei soos wat die geval is by Dawkins en andere. Ware wetenskap sal egter juis in nederige erkenning voor die wonder van God in gebrokenheid, weens die sonde van die mens, die beperkings van die wetenskap erken. Die hubris van die westerse wetenskapsbeskouing lei tot 'n gebrek aan erkenning van die uiterste gevare wat daarmee gepaard gaan, byvoorbeeld kernenergie. Wetenskap wat nie grense erken nie, maar wat ongebreideld voortgaan om die skepping uit te buit en te vernietig, sal ook nie God se reg eken nie. Waar die wet van God oortree word, word die grense van die wetenskap oorskry. Hierdie oorskryding kom byvoorbeeld ook voor wanneer die mediese wetenskap 'n lewe neem om daardeur te genees.

\section{Wetenskapsbeoefening vanuit 'n eskatologiese perspektief dui aan dat die lewe hier en nou tydelik is en dat die toekoms deur God bepaal word}

Die humanistiese en sekularistiese wetenskap is dikwels op die hier en die nou gerig. Dit is asof die groot eskatologiese perspektief en die strewe na universele waarhede afwesig is. 'n Suiwer perspektief op die wetenskap sal juis aandui dat God die lewe bepaal en dat daar meer is as die lewe van die hier en die nou. Sonder 'n perspektief op die ewigheid loop die wetenskap die gevaar om totaal immanent te word en die reikwydte van God se heerlikheid mis te loop.

\section{Die soeke na geregtigheid wat in God gevind word}

Die vraag na geregtigheid is indringend, omdat dit die lewe óf positief, óf negatief bepaal. Geregtigheid is egter 'n uiters moeilike begrip om te bepaal. Alleen God kan die ware betekenis daarvan aandui. Indien die perspektief vanuit God se beslissing daaroor nie gesoek word nie, ontspoor dit. 'n Wetenskapsbeskouing wat nie deeglik kennis neem van die geregtigheid wat van God kom nie, neem die mens as uitgangspunt en postuleer dan geregtigheid op 'n humanistiese wyse. Dit lei dikwels tot die miskenning van die reg van ander.

\section{Die volle voltooiing van die implikasies van die nuwe hoop wat God gee}

Wetenskapsbeoefening moet die nuwe werklikheid dien waarvan hoop 'n intrinsieke deel moet wees. Die volle hoop wat God gee, rig die wetenskap op die toekoms. Daardeur verkry die mens self hoop wat verruim word. Van der Walt (1999b:56) dui twee sake aan wat in die vernuwing van groot belang is. Die een is reformasie en die ander herlewing. Reformasie kan vergelyk word met die ploeg van die land en herlewing met die Heilige Gees wat reën gee sodat die gesaaides kan groei. Dit is twee kante van dieselfde saak, naamlik vernuwing. Lewensvisie en lewenswandel vorm volgens Van der Walt (1999b:56) 'n onlosmaaklike band.

Dit is duidelik dat slegs in die nuwe lewe voor God, hoop op die toekoms moontlik is. Hierdie hoop spruit uit die vernuwende lewensvisie wat ook die wetenskapsbeoefening raak. In Christus word die verwagting van die nuwe lewe 'n werklikheid. Neely (1984) skryf:

The invitation is not to withdraw and form a new circle of monastics, but to prove the revolutionary effects of opening one's life to God in a disciplined, daily awareness and communion. (bl. 85)

\section{Slot}

Die nuwe godsdiens van die Weste is radikaal en omvattend. Vir die verlossende genade in Jesus Christus en die lewensvisie wat op God se wederbarende krag gerig is, is daar egter weinig plek. Die reformatoriese vernuwing van die samelewing en veral die wetenskap vereis die erkenning van Jesus Christus se lewensomvattende invloed en heerskappy. Alleen in die erkenning van Christus as die Here kan daar opnuut herlewing in die Weste kom, met 'n diepgaande erkenning van die majesteit van die ware God. 'n Lewensvisie wat Hom erken, is dringend noodsaaklik om die verlies aan die ware hoop teen te werk. Hierdie artikel wil aantoon dat daar op 'n nuwe en radikale wyse Trinitaries gedink moet word. Beginsels wat reeds vroeër vasgelê is, moet weer opnuut beklemtoon word. Dit is juis die gebrek aan 'n diep Christelike totaalvisie wat die ontsporing in die 
lewensbeskouing en die wetenskap in die Weste meebring. Die voortdurende bevestiging van die heil wat van God kom, is juis onder die huidige omstandighede essensieel.

\section{Erkenning Mededingende belange}

Die outeur verklaar dat hy geen finansiële of persoonlike verbintenis het met enige party wat hom nadelig kon beïnloed het in die skryf van hierdie artikel nie.

\section{Literatuurverwysings}

Anidjar, G., 2002, 'Introduction "once more, once more": Derrida, the Arab, the Jew', in J. Derrida, Acts of religion, pp. 1-39, Routledge, New York.

Berkhof, H., 1973, Christelijk geloof, Callenbach, Nijkerk.

Bush, L.R., 1984, 'What is Secularism?' Southwestern Journal of Theology 26(2), 5-14.

Clouser, R., 2006, 'Genesis regained: Creation not creationism', Tydskrif vir Christelike Wetenskap 42(spesiale uitgawe 1), 49-64.

Craffert, P.F., 2002, 'Die Nuwe Hervorming en die historiese Jesus: 'n Verandering van denke', in P. Muller (red.), Die Nuwe Hervorming, pp. 161-176, Protea Boekhuis, Pretoria.

Dawkins, R., 2006, The God delusion, Black Swan, London.

Degenaar, J.J., 1967, Sekularisasie, Akademica, Kaapstad.

Derrida, J., 2002, 'Faith and knowledge', transl. S. Weber, in J. Derrida, Acts of religion, pp. 19-101, Routledge, New York.

Dooyeweerd, H., [1959] 2012,Roots of western culture: Pagan, secular, and Christian options, transl. J. Kraay, newly ed. by D.F.M. Strauss, Paideia Press, Ontario. (The collected works of Herman Dooyeweerd, Ser. B, Vol. 15).

Henry, C.F.H., 1988, Twilight of a great civilization: The drift toward Neo-Paganism, Crossway Books, Westchester.

Heyns, J.A., 1978, Dogmatiek, NG Kerkboekhandel, Pretoria. PMCid:PMC1145538

Janse van Rensburg, J., 2000, The paradigm shift: An introduction to postmodern thought and its implications for theology, Van Schaik, Pretoria.
Klinghoffer, D., 2005, 'That other church, let's face it: Secularism is a religion - Let's treat it as such', Christianity Today, January, p. 62.

Mashau, T.D., 2009, 'A reformed missional perspective on Secularism and Pluralism in Africa: Their impact on African Christianity and the revival of Traditional Religion Calvin Theological Journal 44, 108-126.

McGrath, A. \& McGrath, J.C., 2007, The Dawkins delusion: Atheist fundamentalism and the denial of the Divine, InterVarsity, Downers Grove.

Morris, B., 2006, Religion and anthropology: A critical introduction, Cambridge University Press, Cambridge.

Neely, A., 1984, 'A Christian alternative to Secularism', Southwestern Journal of Theology 26(2), 68-86

Newbigin, L, 1986, The other side of 1984: Questions for the churches, World Counci of Churches, Geneva.

Smith, G., 2010, A short history of Secularism, Taurus, London.

Strauss, D.F.M., 1973, Begrip en idee, Van Gorcum, Assen.

Strauss, D.F.M., 1978a, Kompendium vir studente in die Wysbegeerte en die Wysgerige Pedagogiek, Deel 1, Butterworth, Durban.

Strauss, D.F.M., 1978b, Inleiding tot die Kosmologie, Sacum, Bloemfontein

Strauss, D.F.M., 1990, Die mens en sy wêreld, Tekscor, Bloemfontein.

Taylor, C., 2007, A secular age, Harvard University Press, London.

Van de Beek, A., 2008, God doet recht: Eschatologie als christologie, Meinema, Zoetermeer. PMCid:PMC3145203

Van der Walt, B.J., 1984, Mense en gode in Suider-Afrika, Potchefstroomse Universiteit vir Christelike Hoër Onderwys, Potchefstroom. (Wetenskaplike bydraes van die PU vir CHO, Reeks F2, Brosjures van die Instituut vir Reformatoriese Studie nr. 24).

Van der Walt, B.J., 1999a, Visie op die werklikheid: Die bevrydende krag van 'n Christelike lewensbeskouende filosofie, Potchefstroomse Universiteit vir Christelike Hoër Onderwys, Potchefstroom. (Wetenskaplike bydraes van die PU vir CHO, Reeks F3 Versamelde werke van die Instituut vir Reformatoriese Studie nr. 48).

Van der Walt, B.J., 1999b, Kerkvernuwing onderweg na 2000: Visie-missie-konteks, Potchefstroomse Universiteit vir Christelike Hoër Onderwys, Potchefstroom. (Wetenskaplike bydraes van die PU vir CHO, Reeks F1 Instituut vir Reformatoriese Studie nr. 379).

Van der Walt, B.J., 2003, Understanding and rebuilding Africa: From desperation today to expectation for tomorrow, Institute for Contemporary Christianity in Africa, Potchefstroom. PMCid:PMC1180345

Van der Walt, B.J., 2008, 'Die uniekheid van 'n reformatoriese lewensvisie', Tydskrif vir Christelike Wetenskap 44(1, 2), 155-186.

Veith, G.E. (Jr.), 1994, Postmodern times: A Christian guide to contemporary thought and culture, Crossway, Wheaton. PMCid:PMC1234416 